\title{
REFLEXIONES SOBRE EL MÉTODO JURÍDICO Y SOBRE LA EXPERIENCIA JURÍDICA DE LEON HUSSON
}

SUMARIo: 1. La actividad del jurista. Los datos del Derecho: walores insertos en hechos sociales. 2. Categorias formales y categorias reales. 3. Concepto de experiencia juridica. 4. El Derecho no es lógica. 5. Refutación de la diferencia entré cuestión de Derecho y cuestión de hecho. 6. Análisis de la experiencia juridica. Sus varios aspectos y niveles. 7. La idea de la justicia. 8. La determinación de la materia por la forma se expresa por una norma que es una idea. 9. Distinción entre la idea y, los conceptos. 10. Influencia de la práctica. 11. Conclusión.

1. La actividad del jurista. Lós datos del Derecho: valores insertos en hechos sociales

León Husson es un notable y original pensador jurídico francés, quien procede del campo de la filosofia pura. Después, emprendió estudios jurídicos, y por cierto muy a fondo y con una formidable agudeza de análisis.

Su libro principal versa sobre el tema monográfico de Las transforma. ciones de la personalidad. Pero, como subtítulo tiene el de Estudio sobre el pensamiento juridico. Es también notable la introducción que èscribió para un volumen de los Archives de Philosophie du Droit dedicado a la Deontologia $y$ disciplina profesionales (1959-1954).

En la primera de las obras mencionadas Husson asocia estrechamente la investigación jurídica sobre un tema particular a la especulación filosófica. Ofrece recíprocamente entrecruzadas una teoria del pensamiento jurídico y una teoría de la responsabilidad civil, ambas fundadas minuciosamente sobre los tanteos de la jurisprudencia y de la doctrina contemporáneas. Husson considera que las transformaciones recientes de la responsabilidad suministran un campo de exploración para el estudio de la estructura del Derecho y de sus modos de elaboración. Y a la inversa: este problema particular, al igual que otros, puede ser satisfactoriamente aclarado por la luz de un análisis filosófico.

Toda interpretación, como toda creación de una regla jurídica, implica una triple experiencia: el percibir una situación; la conciencia, al menos implícita, de un conjunto de valores; y el intento de artificios libremente imaginados para ajustar aquella situación a estos valores. La integración de esos elementos se opera en una idea, en el sentido objetivo de la palabra, es decir, en un principio de inteligibilidad, en el que se unifican todos los rasgos de la institución en cuestión. Pero esta idea no es, como sucede é el conocimiento positivo de la realidad, una estructura actual, sino una estructura virtual. 
La filosofía del Derecho no adquirirá rigor y precisión sino en la medida en que se decida a salir de las generalidades, para aventurarse en el terreno de la ciencia jurídica.

No se puede determinar a priori el procedimiento ni el alcance del conocimiento humano. La historia de la filosofía atestigua que la teoría del conocimiento se ha nutrido en cada época de la experiencia que el hombre había adquirido de su actividad intelectual, ora espontánea y vulgar, ora científica.

Después de que las cienciaś se han ido diferenciando de la filosofia, ésta ha anudado relaciones estrechas de colaboración con todas las ciencias. Pero la filosofía del Derecho no ha trabado aún un contacto suficientemente intimo con la actividad intelectual del jurisconsulto. Incluso en la axiología jurídica, sería buena táctica comenzar por el análisis de los juicios de valor contenidos en la legislación positiva, sin perjuicio de criticarlos. Pues es más fácil llegar a lo desconocido partiendo de lo conocido.

Por eso Husson se decide a estudiar la actividad intelectual del jurisconsulto, al igual que la filosofía lo hizo desde largo tiempo ha con la actividad de los físicos y de los biólogos. Analizando la actividad intelectual del jurisconsulto, los procedimientos empleados en ésta, e incluso criticándolos, Husson espera determinar lo que este examen puede revelar en relación con la conducta de la mente jurídica, así como también en relación con el objeto, es decir, en relación con el Derecho.

En el análisis del pensamiento jurídico, Husson cree que se puede descubrir una perspectiva que haga, posible confrontar las demandas, a veces rivales, de la sociología y de la filosofía del Derecho. En el pensamiento juridico hallamos siempre la inserción de valores en la trama de los hechos sociales. Husson espera que tomando esto en cuentá, se podrá aclarar considerablemente el difícil problema de las relaciones entre las ciencias normativas y las ciencias de realidades. Una comprensión más profunda del pensamiento jurídico tendrá que llevar a entender mucho mejor el Derecho, la indole de éste, su base, y su contenido.

El Derecho se presenta en dos aspectos diferentes: a) como un dato anterior al pensamiento del jurista -que es así como lo ve el sociólogo-; y b) como un punto de partida para ulteriores tareas de interpretación y aplicación, que deben ser llevadas a cabo por el jurista.

Para la ciencia jurídica el Derecho aparece como situado en la intersección de dos órdenes: el de las razones pensadas por el espiritu; y el de las causas efectuadas en la realidad social histórica. Pero, en todo caso, urge saber que "el Derecho no se actualiza sino expresándose en las conciencias y "poniendo en obra, separada o solidariamente, las actividades individuales".

Con respecto a la diferencia entre la formación del Derecho por el legislador, de una parte, y el conocimiento, interpretación y aplicación del mismo 
por los juristas, de otra parte, Husson crée que se trata tan sólo de una distínción relativa, que tiene como supuesto el hecho de una sociedad muy organizada, donde reina la división del trabajo, la cual se traduce en la separación de la función legislativa y de la función judicial. Pero, incluso en una sociedad tal en la que impere dicha división del trabajo, habrá siemṕre interferencia entre esas dos funciones _-la legislativa y la judicial_-; se dará la colaboración de juristas a la obrá legislativa en plan de consejeros, la su-' plencia de las lagunas por el juez; la elasticidad en la interpretación al servicio de nuevas necesidades, la integración de la regla jurídica con las convicciones sociales vigentes. Por otra parte, el législador casi nunca hace - ni puede hacer - tabla rasa del Derecho preexistente; y sus reformas se refieren a determinadós puntos 0 zonas, pero no a la totalidad del orden jurídico recibido como vigente; e incluso en los movimientos más revolucionarios, el legislador se siente ligado a las convicciones sociales que alientan éstos.

Husson, después de haber descrito muchos titubeos en la jurisprudencia de los tribunales'y discusiones doctrinales, muestra que lás apreciaciones y las estimaciones directas ejercen una gran influencia en el juego de los argumentos. Por tanto, parece que nos encontramos frente no sólo ni tanto a consecuencias obtenidas mediante la deducción, que parte de los principios sobre los cuales se supone que talés consecuencias se basan, sino más bien, nos encontramos ante datos ofrecidos directamente al pensamiento por la consideración de los casos particulares en cuestión.

Aunque las expresiones conceptuales empleadas por abogados, jueces o profesores pueden ser diferentes e incluso antitéticas, sin embargo, todas se refieren a una pareja de ideas inseparables: la de equilibrio; y la de lo mio, lo tuyo y lo suyo.

El Derecho en vigor en una determinada sociedad, no puede constituir más que un conjunto de formas, tras de las cuales hay un factor de poder, si es que no de fuerza. Es de tal suerte, porque lo que constituye la especificidad del Derecho, consiste en que éste prètende, y logra parcialmente, imponerse a aquéllos a quienes rige, no sólo por virtud de la coerción material o moral de quienes lo han establecido o lo hacen respetar, 'sino también, y de un modo más esencial, por una fuerza de. otro orden, análoga a la obligación moral, si es que no se remite a ésta. Esta fuerza análoga a la obligación moral, o emparentada con ella, hace una presión. sobre las conciencias, reclamando la adhesión voluntaria, y determina que la desobediencia sea un entuerto o una falta. De este modo, da a la coerción, cuando es necesario recurrir a ella, ese carácter original que se llama "legitimidad". Por tanto, el Derecho implica, más allá del mandato humano del poder que lo instituye, la aceptación colectiva de la costumbre, o incluso el respeto a la palabra dada, la creencia en una regla, percibida en el fondo de nosotros mismos, y 
que nos domina. Esta creencia, junto con los cambios de las condiciones materiales de la vida, es el motor de la evolución del Derecho. De esta suerte, el Derecho plantea el problema de la necesidad de una explicación de otro orden, sin la cual la acción del Derecho, al igual que su existencia, serían incomprensibles. Así pues, nos encontramos con la idea de un dato que soporta todas las construcciones a las cuales la historia nos hace asistir, por virtud del juego de las reflexiones individuales, de los órganos políticos y de los movimientos de opinión - con independencia, por otra parte, de la indole y del fundamento de este dato. Pero además sucede que las contradicciones entre las doctrinas que han intentado definir el Derecho, y la imprecisión de la mayor parte de ellas, las cuales no han descendido por debajo de la periferia de las generalidades, concurren, junto con la diversidad de los múltiples Derechos positivos y la imposibilidad en que parece que estamos de alcanzar en la experiencia nada más que esta diversidad, a inspirar a los espíritus anhelantes de rigor y de verificación una desconfianza invencible, respecto de toda afirmación de un Derecho Natural, anterior a las instituciones y a-las corrientes de opinión. Advierta el lector que esto constituye sólo el planteamiento ofrecido por Husson, pero no la doctrina de éste, pues Husson acepta una estimativa jurídica inspirada en criterios éticos, no sólo como instancia crítica y orientadora, sino también como componente, al menos en tanto que referencia, de la realidad del Derecho, o, mejor dicho, de la experiencia jurídica:

Las dificultades aludidas tienen repercusión también sobre el uso de las categorías jurídicas, habitualmente empleadas por el jurista para fundamentar su pensamiento. Resulta que, por los motivos esbozados, el prestigio de esas categorias disminuye. Tales categorías, en las que se expresa mejor o peor el tema fundamental de la justicia, son complejas, inestables, y, en su mayor parte, artificiales. A veces el jurista se encuentra con una dualidad o una multiplicidad de categorias diferentes, de cuadros distintos, que, a veces, violentan la realidad de esas situaciones. Se trata nada menos que del problema acerca del papel, de lás condiciones, y del valor de las clasificaciones juridicas.

Con el propósito de descubrir una guía para el problema de las categorías y de las clasificaciones jurídicas, Husson busca inspiración en el campo de las ciencias biológicas. Tal cosa no implica en modo alguno un propósito de tendencia organicista. Nada de eso. Trata tan sólo de buscar una orientación inicial que pueda ofrecerle alguna luz para su problema, que es propiamente de filosofía jurídica. Así, por ejemplo, advierte que el contenido del concepto "mamífero" parece bastante escaso, puesto que comprende lo mismo el perro, el buey, el murciélago y la ballena, e incluso el hombre. Sin embargo, todos ellos presentan una misma arquitectura interna, la cual justifica su agrupación; si bien esta arquitectura se realice en ellos 
bajo formas irreductibles las unas a las otras, y se adapten a géneros de vida igualmente irreductibles. Por tanto, sería necesario distinguir entre dos clases de tipos correspondientes a dos clases de divisiones de la sistemática: tipos formales, los cuales definen las divisiones inferiores; y tipos de organización, que sintetizan las divisiones superiores.

\section{Categorias formales y categorias reales}

Al igual que todas las actividades humanas en las que interviene la inteligencia, él Derecho no comprende solamente las clasificaciones virtuales, implicadas en los conceptos, y en el lenguaje por medio del cual se expresan. Por razón de su carácter de norma social, el Derecho requiere mucho más: requiere la constitución expresa de clases netamente especificadas. Pues la eficacia del Derecho, así como la seguridad de aquéllos a quienes el Derecho se refiere, dependen de la precisión y de la firmeza de éste. El medio más natural y el más seguro, si es que no el único, de adquirir esas cualidades, consiste en que el Derecho encierre sus prescripciones en el cuadro de categorias tajantemente distintas y especificadas, a cada una de las cuales se atribuya efectos jurídicos determinados, de suerte que, en presencia de un hecho, se tenga tan sólo que descubrir el compartimento juridico dentro del cual debe encontrar su lugar.

La cosa resulta particularmente clara cuando el legislador, para especificar, sin impugnación posible, los actos juridicos y rodearlos de ciertas garantías, impone a éstos el ropaje exterior de un procedimiento preestablecido. Entonces tenemos que habérnoslas con lo que suele llamarse categorias formales, formas juridicas. Pero esas formas, limitadas necesariamente al dominio de los actos que apuntan conscientemente a un resultado jurídico, no son las únícas. Al lado de ellas nos encontramos con las categorías reales, que definen los hechos por la consideración de sus elementos intrínsecos, y de las cuales, por consiguiente, es posible hacer empleo incluso cuando se trata de hechos que en el pensamiento de su autor no entrañan, una intención jurídica. Las categorías reales constituyen, por ejemplo, la osamenta del Derecho Penal. Ahora bien, las categorías reales parecen a la reflexión como más fundamentales que las categorías formales, o formas de los actos jurídicos. Esto es así, no sólo porque las categorías reales son de uso universal, sino también, además, porque ellas están implícitamente supuestas por el formalismo; pues, si la categoría formal se define por caracteres extrínsecos a los actos que ella abarca, el espíritu no puede crear ni imponer las formas al azar. Las categorías formales, una vez establecidas, eximen de analizar en una gran medida los actos en sí mismos, y sirven para cubrir actos intrínsecamente diferentes.

La elaboración intelectual del Derecho, así como también el manejo 
práctico de éste, entrañan una especie de invitación a las clasificaciones. $Y$ aún se diría mejor no una invitación, sino una serie de invitaciones en gran medida independientes. Pues el Derecho, incluso cuando su elaboración revista la forma legislativa, y todavía mucho más, cuando es la obra de la jurisprudencia o de la costumbre, no toma nunca súbitamente, ni en bloque total, una forma propiamente sistemática, forma que jamás podría conservar sin grändes esfuerzos y notable violencia. Por el contrario, sigue un método diferente: se guía y orienta por el camino de disposiciones distintas, cada una de las cuales apunta a la solución de un orden particular de problemas, si es que no de un problema aislado. Adviértase además que ese orden particular de problemas, la mayor parte de las veces, va modificándose a través de los cambios sociales. Ahora bien, no solamente la suma de esas disposiciones no podría constituir un conjunto completo, pues tiene que dejar subsistir durante largo tiempo enormes lagunas; sino que, además, puesto que los rasgos que atraen la ațención son muy diferentes a tenor de cuáles sean los problemas de que se trate, tanto que cada uno de ellos es resuelto en cuanto a sí mismo, las categorías manejadas para su solución están muy lejos de prestarse a una organización sistemática. Es más, puede suceder que esas categorías se enreden o enmarañen las unas con las otras. Cierto que intervienen algunas nociones comunes de relativa constancia, la cual se traduce en el lenguaje por el retorno frecuente de los'mismos términos. Cierto que tambićn la analogia desempeña un papel importante en la determinación de las categorías, $y$, todavía más, en la determinación de los efectos jurídicos ligados a cada una de ellas. Cierto asimismo que esas categorías proceden de un mismo movimiento del pensamiento, cuya orientación general permitirá al historiador referirla a algunas líneas más o menos simples. Ahora bien, nada de todo eso implica una sistematización consciente. Para hallar una sistematización, la cual en todo caso dependerá en mayor o menor medida de cada una de las situaciones, y que, a lo sumo, podrá tan sólo ser esbozada, es necesario referirse a las colecciones de los prácticos y a los trabajos de la doctrina, o bien, a las compilaciones de costumbres y a las codificaciones. Pero todas esas cosas suponen un Derecho ya existente, incluso las codificaciones, las cuales apuntan sin duda a renovar el Derecho tanto como a organizarlo, pero que no pueden conseguir y realizar esa renovación nada más que en función de su estado precedente.

En realidad, la sistematización que se intenta, responde en el fondo a menesteres prácticos en el désempeño de la profesión jurídica: responde al deseo de poder encontrar fácilmente, entre la multitud de las normas jurídicas, aquéllas relativas a la especie del caso planteado. Ahora bien, cuando comprendemos esto, advertimos que para satisfacer ese menester práctico, no se requiere una verdadera y auténtica sistematización. Los prácticos del Derecho se suelen acomodar a clasificaciones empíricas e incluso toscas. 
El pensamiento jurídico no cuenta con un Linnco ni con un Cuvier. Ahora bien, las clasificaciones jurídicas se aplican a objetos enteramente diferentes de los objetos de las clasificaciones biológicas; y las clasificaciones jurídicas se colocan en un punto de vista por completo diferente. La biologia, ciencia positiva, se ocupà de seres materiales. En cambio, la ciencia del Derecho tiene por materia situaciones y actos humanos, es decir, hechos que, aun cuando se inserten en realidades materiales, ellos no son propiamente materiales. Además, la ciencia jurídica no presta atención al modo' como ésás realidades se desenvuelven de hecho, antes bien, a las normas socialmente sancionadas o sancionables, a las cuales los actos humanos están sometidos. Por tanto, la ciencia jurídica no apunta a definir y clasificar esos actos humanos en sí mismos, según su estructura psicológica o social, sino en función de un cierto orden de valores.

No es posible resumir, ni siquiera en términos muy sucintos, los finisimos análisis llevados a cabo por. Husson sobre las categorías jurídicas, y sobre el desarrollo de los datos jurídicos, todo ello en estricta relación con el examen que ofrece sobre las transformaciones de la responsabilidad. Pero; en cambio, aunque sea nada más que en forma muy somera, conviene decir algo sobre el concepto que Husson tiene de lo que él llama expériencia jurídica.

\section{Concepto de experiencia juridica}

El trabajo del jurista no se reduce en manera alguna a las operaciones lógicas mediante las cuales suele formularse. Reconocerlo así no implica que uño no se dé cuenta de que las operaciones mentales del jurista son rigorosas y precisas. Esas operaciones mentales imponen una forma bastante estricta al desarrollo del Derecho; y oponen una resistencia, a menudo victoriosa, a las pretensiones de las partes y a las intenciones del intérprete. Pero esas operaciones mentales están subordinadas a otras, están reguladas de modo más o menos explícito por otras. El pensamiento lógico maneja conceptos y se atiene a principios: una vez definidos esos conceptos y establecidos esos principios, la deducción opera de modo soberano. Pero basta con retocar los conceptos o con añadir a los principios otros nuevos, para que las conclusiones queden inmediatamente modificadas. Mucho más importantes y esenciales que la deducción son las operaciones por medio de las que el jurista elabora las ideas y concibe las relaciones básicas entre éstas. El Derecho no es un sistema hipotético-deductivo: se refiere a realidades dadas, a los conflictos de intereses que surgen en la vida social; y apunta hacia aplicar a éstos una regla de justiciă que responde a una aspiración profunda de nuestro ser humano. Por tanto, las nóciones y los principios del jurista no pueden de ninguna manera ser asimilados, ni siquiera comparados, a los 
conceptos y a los principios matemáticos. Los conceptos y los principios jurídicos se parecen mucho más a las nociones y a los principios empleados en las ciencias experimentales; pues, de modo análogo a éstos, son el producto de una organización intelectual de los datos. Esto es evidente por lo que atañe al conocimiento de los hechos que el Derecho está llamado a regir, conocimiento que constituye la parte positiva del Derecho. Ese conocimiento implica la abstracción, la generalización y la inducción amplificadora, todo lo cual, propiamente hablando, no es un razonamiento sino que es un método. Y eso aparece igualmente cierto, cuando uno piensa en la parte normativa; pues las exigencias de la justicia antes de ser pensadas son sentidas; y es, precisamente en sus aplicaciones concretas como las captamos mejor. Aunque haya aquí un verdadero esfuerzo de conceptualización y de inducción, sín embargo se da una diferencia, importante y esencial, a saber: 'los hechos no suministran la prueba material de las verdades sobre las cuales arrojan luz, sino que ofrecen más bien la ilustración de esas verdades. No es la inducción científica la que establece una ley, generalizando aquello que ha sido constatado efectivamente en ciertos casos. Se trata más bien de la inducción socrática, que lleva al espíritu a la cunciencia de una convicción moral, haciéndole reflexionar sobre los hechos. Por tanto, en el-pensamiento jurídico es necesario no sólo, considerar el movimiento del espíritu que define y encadena las ideas, sino que hace falta considerar, todavía mucho más, el vaivén por el cual el espíritu desprende de los hechos unas ideas y aplica éstas a aquéllos.

Una vez más, Husson insiste en que entre la llamada creación del Derecho y la interpretación de éste no existe una linea tajante de demarcación. $\mathrm{E}$ insiste también en que el Derecho no se halla contenido por completo en los principios en que suele formularse, antes bien, tiene una especie de trasfondo fuera de esos preceptos. Sus preceptos no son nada más que expresiones parciales de ese trasfondo.

\section{El Derecho no es lógica}

Una definición matemática se basta a sí misma, porque es válida dentro de los límites de la no contradicción. Un postulado matemático vale pòr sí mismo, porque es convencional. Por el cóntrario, una definición juridica designa una categoria de operaciones o de situaciones reales, de la cual se puede deducir más o menos felizmente la indole y los signos distinguidos; y, por tanto, es inevitablemente relativa a la experiencia de aquéllos que la han formulado. Una regla jurídica, incluso la que no lleva la huella de ciertas necesidades prácticas relativas a su ejecución, tiende a expresar las exigencias de la justicia, tal y como éstas aparecieron a sus autores, y, por ende, se aplica tan sólo a los casos para los cuales fue hecha. No hay nada en abso- 
luto que pruebe que su fórmula, en presencia de situaciones nuevas, que los autores de la norma no pudieron prever, no resulte o demasiado amplia o demasiado estrecha.

Por muy estricto que el método del jurista quiera ser, el intérprete no puede prácticamente tomar las fórmulas legales o consuetudinarias como autosuficientes, como bastándose a sí mismas. Por el contrario, el intérprete debe considerarlas como la expresión de un pensamiento sub-yacente que esas normas traducen mejor o peor, y que llegado el caso podría suceder que incluso traicionasen ese pensamiento.

Así, pues, las normas jurídicas, las definiciones jurídicas, y la interpretación jurídica no constituyen problemas de lógica, sino problemas de apreciación. En estos asuntos hay lugar para apreciaciones, porque los conceptos de las instituciones del Derecho positivo no son conceptos ideales, antes bien, expresan tan sólo realidades psicológicas y sociales.

Pero la apreciación del intérprete no se detiene ahí. Va más lejos. Se detendría ahí, tan sólo si sucediese que la inducción y la conceptualización incumbieran exclusivamente al legislador que elabora la regla, de suerte que al intérprete no le quedase después nada más que la tarea de comprender el pensamiento del legislador pära extraer las consecuencias. Ahora bien, el intérprete se encuentra ante la labor no tanto de deducir consecuencias, cuanto más bien de resolver especies concretas.

La deducción opera sobre conceptos. Por el contrario, lo que le es dado al juez son hechos; de módo que el juez tiene que aplicar los conceptos a los hechos. Por ejemplo, es una regla positiva en muchos ordenamientos jurídicos que el contrato de transporte implica a cargo del transportador el deber de conducir al viajero sano y salvo a su destino. Esta norma impone la condenación del transportador en caso de daños, con excepción del caso fortuito, de la fuerza mayor, de la responsabilidad de un tercero, o de una falta de la víctima. Algunas veces se planteó el problema de saber si en determinados casos había un contrato de transporte; y si no había ni caso fortuito ni fuerza mayor, ni culpa de la yíctima. Unos dicen: "el contrato resulta de una concordancia de consentimientos; ahora bien, en el transporte benévolo se establece una concordancia de consentimientos; luego, el transporte benévolo implica un contrato". Pero otros contestan: "el contrato supone la intención de ligarse; ahora bien, esta intención no existe en el espiritu del transportador benévolo; luego, el transporte benévolo no implica un contrato". Desde el punto de vista lógico, estas dos deducciones son válidas; pero claro que todo depende de la elección que se haga de las premisas. Se solía considerar cada uno de esos componentes, las dos premisas y la conclusión, como partes separadas; y se solía decir que la premisa mayor constituye la cuestión de Derecho, y la menor la cuestión de hecho. Habitualmente se decía que la premisa mayor debe ser suministrada por los 
principios consagrados o por los textós legales; y que solamente la premisa menor quedaba entregada a la apreciación del intérprete, y que ella era objeto de constatación. Pero las cosas están infinitamente lejos de ser tan simples, como se pretende en esos enunciados. La cuestión de hecho, generalizada por inducción, podrá perfectamente en un caso, como el de este ejemplo, convertirse en objeto de un precepto general del legislador 'o de un control de la Corte Suprema. Nótese que la constatación que se deja al intérprete no consiste tan sólo en establecer, mediante pruebas o presunciones, la materialidad de los hechos, sino que consiste también en descubrir la calificación de esos hechos, es decir, consiste en apreciar cuáles son los conceptos bajo los cuales esos hechos pueden ser subsumidos. Ahora bien, esta calificación puede no ofrecer dificultadesı cuando la ley ha enumerado, de modo preciso y limitativo, las condiciones de aplicación de sus normas; y cuando las condiciones indicadas aparecen netamente y sin complicación en los hechos. Pero, cuando la categoría jurídica es un poco amplia, o cuando el hecho es complejo, o. cuando, sin'ser particularmente complejo, el hecho no presenta exactamente los criterios de ninguna de las categorias preconstituidas, entonces el margen de apreciación se ensancha en gran medida. Es lo que ha sucedido respecto del transporte benévolo. Sobre este punto el legislador no había emitido ninguna regla especial. Entonces, era menester hacerlo entrar en una categoría más amplia. Ahora bien, aun suponiendo que las categorias en las que se quisiera encajar ese caso hubieran sido definidas con una precisión que no dejase lugar a duda sobre sus caracteres definidos, entonces quedaría todavía el problema de encontrar esos caracteres en los hechos. Esos hechos son complejos. Mediante el análisis se puede discernir en ellos, por una parte, algunos de los caracteres contenidos en la definición de una categoría. Pero también se puede descubrir en esos mismos hechos otros caracteres por los cuales se acercan a otra categoría. Y asimismo se puede hallar en esos hechos otros caracteres que les son propios. Entonces se ve que resultan posibles muy diferentes calificaciones. En un caso como éste, la operación esencial que determina la acción no es en absoluto, de ninguna manera, una operación lógica, por virtud de la cual, la premisa menor se coloque bajo la mayor. Se trata de un acto del espíritu que no solamente es diferente de las operaciones de conceptualización y de inducción, por las cuales ha sido definida la categoria y puesta la regla. Se trata de un acto que además constituye precisamente lo inverso de las operaciones de conceptualización y de inducción. Se trata de abstraer de la realidad concreta los elementos inteligibles que permiten pensarla.

5. Refutación de la diferencia entre cuestión de Derecho y cuestión de hecho Esas consideraciones ponen en evidencia que se debe rechazar la distin- 
ción clásica entre cuestión de Derecho y cuestión de hecho. Cuando hacemos a un lado esta distinción, entonces se esfuma también la diferencia tajante entre legislación y jurisprudencia. Al acercar mutuamente de modo estrecho las dos tareas que se imponen al intérprete, es decir, la interpretación de la ley - par̉a definir cuál es el verdadero sentido de ésta_, y la interpretación de los hechos - para conceptualizarlos en uno de los sistemas que ofrezca la ley-, entonces, al entrelazar esas dos tareas, con eso se ofrece el medio de adaptar en una medidá muy grande las normas antiguas a las necesidades nuevas. La forma de expresión que se ha empleado para describir esas dos tareas del juez es incorrecta, porque podría sugerir que el juez resuelve la cuestión de Derecho y la cuestión de hecho, la una con independencia de la otra, determinando el sentido de la ley en el plano abstracto, y buscando la calificación legal del hecho sin haber tomado en cuenta las consecuencias que ésta traerá consigo. Las cosas pueden suceder así ẹ una interpretación doctrinal, o incluso en una interpretación en la que se trata de especies clásicas que entran por sí mismas dentro de las categorias definidas con precisión, y para las cuáles la solución consagrada no suscita ninguna duda. Pero no sucede lo mismo cuando faltan categorías precisas o cuando el caso planteado no es clásico, o cuando la solución es seriamente discutible y se trata de evitarla. Entonces, aunque en apariencia la argumentación desenvuelta se asemeje a un silogismo cuya premisa de Derecho es la mayor, y cuya premisa de hecho es la menor, en realidad sucede que este silogismo generalmente es tan sólo la forma dada con posterioridad a otro tipo de pensamiento que se tuvo antes; y se acude después al silogismo para precisar, verificar y justificar ese pensamiento.

Creo oportuno, muy conveniente, llamar la atención del lector sobre la impresionante concordancia de estas observaciones de Husson con las formuladas por los más ilustres representantes del movimiento del realismo jurídico norteamericano, de modo especial, por Llewellyn y Frank. Y parece que esos pensamientos, o mejor dicho, esas observaciones y esos análisis, se le han ocurrido a Husson por cuenta propia, y no por haber sido influido por los realistas estadounidenses. En muchas sentencias, si las analizamos bien, se percibe que el meollo de las mismas, el fallo entrelazado con los hechos calificados y con la norma, fue percibido o afirmado directamente antes de haberse procedido a justificarlo por una argumentación formal de índole silogística. Esa argumentación formal parece el simple desarrollo del juicio intuitivo. Después de haberse producido tal juicio intuitivo, se aplica a él una especie de análisis racional. Con ese análisis racional la sentencia puede perder en exactitud lo que gane en apariencia de rigor y precisión.

Pero, en todo caso, la interpretación del texto y la de los hechos no son independientes: el texto es interpretado en vista de su aplicación a los hechos; así como los hechos son analizados en vista de su relación con los textos. 
Así pues, el intérprete se asociá al trabajo del legislador. Claro que el intérprete queda subordinado al legislador, y debe contar con el contenido de las nociones y de las fórmulas legales; pero el intérprete precisa o amplía, atenúa o refuerza, incluso a veces corrige el sentido de los textos, de acuerdo con los datos de su experiencia y según el veredicto de su juicio. Para esto el procedimiento más directo consiste en desprender, por abstracción, de la especie considerada un carácter particular, que la pone fuera de las categorías preconstituidas.

Nos. encontramos, pues, ante un movimiento que ha impulsado a los intérpretes a ampliar su tarea hasta el punto de colaborar en la obra del legislador y de rebasar el plan de los preceptos legales, para buscar más allá la verdadera sustancia del Derecho. Esto se explica por la presencia de un pensamiento concreto por debajo del pensamiento abstracto y formal -del que se ocupa la lógica tradicional. Ahora bien, para descubrir la incógnita o las incógnitas de las cuales depende toda la vida juridica, no hay más que someter ese pensamiento concreto a análisis. El acto de un espíritu que no procede 'de un modo puramente constructivo, sino que trabaja sobre un dato, es lo que se llama en el lenguaje científico una experiencia. Y toda experiencia supone un dato, que ella se esfuerza en asimilar, y, en caso necesario, en transformarlo y en añadirle algo.

\section{Análisis de la experiencia juridica. Sus varios aspectos y niveles}

Así pues, toda esa investigación desemboca en la noción de una experien. cia juridica'. La clave de la teoría del Derecho se'encontraría, pues, en la crítica de esa experiencia.

Cierto que la noción de una experiencia jurídica está lejos de ser perfectamente clara y que ella suscita resistencias y malentendidos. Husson dice que esa noción de experiencia jurídica se inserta en el marco de-otras experiencias, como la experiencia moral y la experiencia religiosa. Es decir, aquí la noción de experiencia se empléa en un sentido mucho más amplio que en el de la acepción corriente de esta palabra; no se refiere a la experiencia de la percepción sensible y del conocimiento psicológico, explorados por la ciencia, sino que va mucho más allá.

Esta extensión del concepto de experiencia se halla ya apuntada por Maine de Biran, y ya más desenvuelta por Bergson. Así pues, se distinguèn diversos planos o niveles de experiencia. Al lado o más allá de la experiencia sensible y de la experiencia psicológica, hallamos̃ una experiencia moral, una experiencia metáfísica, una experiencia religiosa, a las cuales hay que añadir una experiencia jurídica: La tarea de la filosofía consistiría en ocuparse de la experiencra integral.

El núcleo o la médula de esa noción más amplia de experiencia, se halla 
en la idea de una instrucción adquirida por el uso o por la práctica, de un conocimiento que el espíritu no saca de su propio fondo. Pero cuando se intenta precisar esta idea definiendo la índole de tal instrucción, su origen, su modo de adquisición, entonces se percibe que esa idea puede ser entendida de dos modos distintos, los cuales, sin embargo, están generalmente asociados. Uno de esos modos es el de un contacto con la naturaleza, de un enriquecimiento que proviene desde fuera, de la asimilación de un dato, en suma, que proviene de una especie de don que se recoge. El otro modo es el de un ensayo, de un intento, de una prueba, de una tentativa; por consiguiente, de algo contrario o mejor dicho distinto del primer modo, es decir, un despliegue de actividad. El primer modo se presenta bajo una forma aproximadamente pura en los filósofos empiristas de los siglos xvir y xvıI, de aquellos filósofos que concebian el espíritu como una tabla rasa sobre la cual vendrían a inscribirse las impresiones. El segundo modo señala el término extremo del nominalismo científico y del pragmatismo, según los cuales la verdad debe ser considerada como nuestra obra. Estos dos modos se combinan ambos en la noción corriente de la experiencia científica, en la libre invención del sabio, que fuerza la naturaleza a descubrir sus secretos $y$, también, de una manera por completo distinta, en la concepción kantiana que considera la experiencia como la organización por el espíritu, según las exigencias propias de éste, de una materia recibida desde el exterior. El origen común así como el vínculo de esos dos modos, se encuentra en las acepciones vulgares, que presentan la misma dualidad y nos remiten a su fuente. En efecto, el lenguaje corriente habla también de la experiencia de la enfermedad o del sufrimiento, que se padece, y de las experiencias que uno emprende, de las experiencias de sus fuerzas, o de las experiencias de un procedimiento técnico. Tanto de unas como de otras, el lenguaje cotidiano dice casi indiferentemente que se hace tal o cual experiencia y que de ella se recibe una lección. Ahora bien, es fácil ver que en los dos casos hay algo de común: un encuentro, y por asi decirlo, un duelo, en el cual nos medimos a nosotros mismos con lo real. Por otra parte, puede suceder que esa realidad, con la que tenemos que habérnoslas, sea nuestra propia naturaleza, en tanto que ésta nos es dada; entonces, tal naturaleza nos aparece también como una resistencia que es necesario vencer, o con la cual es necesario avenirse.

Después de haber emprendido un análisis etimológico, Husson llega a la conclusión de que la idea originaria sería la que traducimos familiarmente hoy en día por medio de metáforas tales, como la de "echarse al agua", "poner mano en la masa"; de lo cual se habría pasado a la idea de empresa, para desembocar al fin, por vía de consecuencia, en la idea de saber. También los filósofos mismos parecen haber concebido ante todo la experiencia como un saber hacer adquirido por la práctica; así pues, como una acumulación de recetas que se han revelado como eficaces en el uso, acumulación revestida y 
reforzada por una aptitud ejercida para ponerlas en obra. Ahora bien, en este sentido, al igual que en el uso vulgar de esta palabra, la experiencia rebasa el ámbito del conocimiento: es esencialmente algo vivido ,y, en tanto que tal, transforma, o mejor dicho informa, el ser entero. La experiencia despierta instintos, impulsos, establece actos, educa la voluntad, determina las maneras de sentir, así como también ilumina el espíritu. Desde el punto de vista intelectual, su función consiste en agudizar el espíritu, tanto y todavía más que en suministrarle materiales.

Cuando el término experiencia se emplea aplicado especialmente al conocimiento, entonces será importante distinguir netamente las dos ideas que ese término lleva consigo: $a$ ) en qué medida el espíritu logra captar los objetos preexistentes; y $b$ ) en qué medida, por el contrario, el espíritu crea lo que se representa. La actividad cognoscitiva no se destaca sino por abstracción del conjunto de las funciones psíquicas de las cuales es solidaria.

Ampliando considerablemente, en gran medida, la extensión que el concepto de experiencia tenía en el mundo de las ciencias naturales -es decir, el sentido restringido del vocablo experiencia dentro del marco del empirismo clásico (antiguo y moderno) _ se introduce esta noción en el dominio del conocimiento metafísico y de la fe religiosa, áreas situadas más allá del mundo de nuestra percepción exterior y de las ciencias positivas; y se la introduce también en los campos de la moral y del Derecho, campos que tienen por objeto juicios de valor y preceptos, en lugar de constataciones y de leyes meramente enunciativas.

Será necesario llamar experiencia, de un modo general, todo conocimiento en el cual el espíritu se encuentra ante un dato, cualquiera que sea la índole de este dato, y cualquiera que sea la parte de construcción que superponga a ese dato. Se tendrá que distinguir en su extensión - según las diversas regiones de este dominio-, una gama de formas, tan diferentes las unas de las otras, que apenas formarán un género. $\mathrm{Y}$ así, la palabrà experiencia cesará de ser un término unívoco, para convertirse en un término análogo o analógico, como dirían los escolásticos.

Husson analiza los diversos aspectos de la experiencia jurídica. Se ocupa primero de la formación de los usos y costumbres que, junto con el arbitraje, constituyen las formas espontáneas del Derecho positivo.

La experiencia juridica interviene también en la legislación. A este respecto Husson se refiere a algunas de las ideas expuestas por Portalis en su famoso discurso preliminar del Código Civil de Napoleón. Según Portalis, el legislador debe fundarse sobre instituciones existentes, y no modificarlas sino con mucha prudencia. Pues las leyes deben estar adaptadas al pueblo para el cual son hechas; deben ofrecer una cierta estabilidad. La superposición y entrecruce de generaciones, así como la adhesión de los hombres a sus costumbres, hacen peligrosas las rupturas demasiado bruscas. El dominio de la 
vida, al cual las leyes se refieren, es el dominio de lo relativo, en el cual lo mejor es enemigo de lo bueno. En relación con esto, Husson observa que la legislación tiene que habérselas con hombres reales, infinitamente complejos, en los cuales la naturaleza de la especie se realiza de modos diversos. Por eso, la legislación es una obra delicada, que debe apoyarse sobre la observación, y que requiere una puesta en práctica progresiva. De nuevo recuerda una expresión de Portalis: "Los códigos de los pueblos se hacen con el tiempo; pero para hablar con propiedad, uno no los hace".

Una concepción tal de la labor legislativa conduce naturalmente a reconocer los límites de esa tarea. Portalis atacó terminantemente la opinión, muy extendida, de'que en la redacción de un código civil, algunos textos bien precisos sobre cada materia pueden bastar, y que a este respecto el verdadero . arte consiste en simplificarlo todo" y en preverlo todo. Ahora bien, es imposible preverlo todo. Hay una infinita variedad de relaciones humanas, que obliga al legislador a multiplicar las hipótesis, pero sin que jamás pueda llegar a agotarlas; pues la evolución constante plantea sin cesar nuevos problemas. La superposición y entrecruce de esas 'realidades, su' relatividad, la finura de los matices que implican, hace imposible la realización de ese propósito de preverlo todo. Por eso, es indispensablemente necesaria la jurisprudenciá, englobando bajo este nombre la ciencia y el arte del Derecho por entero, tal y como son profesadós por los jurisconsultos, así como por los magistrados; y todo eso unido al conjunto de las máximas, de los usō̌ y de las costumbres, de las opiniones y de los precedentes. La misión de la ley es fijar en grandes perspectivas.las máximas generales del Derecho; la de establecer, principiós fecundos en consecuencias, sin descender al detalle de los problemas que pueden surgir en cada materia. Compete al magistrado y al jurisconsulto, penetrados del espíritu general de las leyes, el dirigir la aplicación de éstas. Ahora bien, esta aplicación no consiste tan sólo en combinar las leyes unas con otras y en adaptarlas a las circunstancias. Consiste también, a veces, en flexibilizarlas para evitar que la letra mate el espíritu de ellas, o bien en colmar las lagunas refiriéndose a la tradición y a los usos, o en tomar en cuenta lós principios naturales de la equidad. Se trata de una tarea muy compleja, cuyo objeto directo es la resolución de los casos particulares, y especialmente de los casos raros y extraordinarios, pero que eventualmente puede iluminar al legislador mismo y señalar el camino a éste. Ahora bien, Portalis no titubeó en definir esta tarea como una obra de experiencia.

El pensamiento jurídico contemporáneo, reaccionando terminantemente. coñtra la doctrina de la exégesis, ha extendido en gran medida esos puntos de vista de Portalis. Se ha llamado la atención sobre la necesidad, en que están tanto los tribunales como la doctrina, de recurrir, quiéranlo o no, consciente o inconscientemente, a los datos y a las sugestiones que les suministra el contacto con las realidades. 
Así pues, la noción de experiencia es invocada en todas las fases de la vida del Derecho, tal y como en efecto se desenvuelve en nuestra sociedad actual. E1 Derecho no puede ser construido enteramente a priori, de una vez y para siempre, antes bien, su enunciado y su aplicación suponen el conocimiento de los hechos̀ que las normas jurídicas rigen; suponen un conocimiento concreto, sugerente, y, por así decirlo, un conocimiento vivido, una verdadera familiaridad con las realidades. Suponen, además, que el contenido y el valor del Derecho se revelan plenamente tan sólo a través del empleo práctico; y suponen que las fórmulas en las cuales se traduce el Derecho deben ser incesantemente adaptadas, retocadas, refundidas, en función de las circunstancias y de las reflexiones que esas circunstancias suscitan.

Para percatarse bien del sentido y de todo el contenido de la experiencia jurídica, es necesario distinguir, y coordinar entre sí varios aspectos de ella.

En primer lugar, Husson dice que en el sentido más fuerte y plenario del término, la experiencia jurídica comprende la idea de un ensayo o de un tanteo, o de una tentativa, cuyo resultado consiste en hacer evidente, no sólo la correcta fundamentación de una hipótesis, sino también la eficacia de un procedimiento. No se debe olvidar jamás que el Derecho no es un enunciado especulativo, antes bien, un procedimiento práctico. El Derecho no pretende solamente definir un ideal, antes bien, establecer asimismo los modos de realización de éste. Ahora bien, las exigencias de lo ideal se determinan tan sólo en función de las circunstancias.

Por eso, el jurista necesita la experimentación en grado mucho mayor todavía que el físico o el biólogo. El problema para el jurista no consiste sólo, cual acontece påra el físico, en confirmar una relación supuesta. Consiste en algo más: en poner a prueba artificios creados libremente, respecto de los cuales es imposible prever a priori todas las incidencias a que pueden dar lugar; y cuyo éxito depende, no sólo de su propio valor, sino también y sobre todo de la docilidad o de la resistencia que encuentren. Toda ley, toda institución, todo régimen político nuevo, constituyen un esfuerzo para realizar prácticamente ciertas finalidades cuy eficacia se juzga por sus resultados.

Este primer aspecto de la experiencia jurídica aclara no solamente el trabajo del pensamiento del jurista; además, nos abre también perspectivas sobre la naturaleza y la estructura del Derecho, permitiéndonos discernir en éste toda una serie de estratos. Los estratos más superficiales presentan la huella de las contingencias de la historia, mientras que los más profundos expresan una realidad estable, que escapa a la acción de esas contingenciàs.

Las variaciones del Derecho positivo no excluyen la existencia del Derecho Natural. Esas variaciones, por el contrario, se concilian perfectamente con la afirmación del Derecho Natural, si se define éste como un conjunto de exigencias y de directrices que gobiernan y deben gobernar la elaboración de los Derechos positivos, directrices que se imponen a las conciencias, 
pero que no pueden tomar cuerpo sino encarnándose en las prescripciones relativas a las circunstancias de su aplicación, cuya formulación, por otra parte, queda librada a la-inteligencia humana, con todos los peligros de error y de equivocación que esto lleva consigo.

Husson acepta la distinción hecha por Lalande, entre razón constituyente y razón constituida. I a razón constituyente es el conjunto de las ideas y de las reglas adquiridas en una determinada época, de los "principios racionales", cuya lista se puede hacer en términos más o menos precisos hoy en día para los pueblos civilizados. Esta razón, que se puede expresar médiante fórmulas, se transforma lentamente a través de las edades, a medida que la reflexión de los hombres profundiza y a medida que se extiende su experiencia, no sin padecer la influencia de las circunstancias, que depositan sobre ella su huella accidental —ni tampoco dejando de estar expuesta a sufrir regresiones. Pero esas transformaciones no son de cualquier índole, no son fortuitas; por el contrairio, se hallan orientadas en un cierto sentido y oscilan alrededor de un cierto eje, cuya constancia nos revela precisamente la permanencia de la función-de la cual ellas proceden. En efecto, bajo la razón constituida, existe una razón constituyente, que no se puede formular de modo adecuado, porque ella no consiste en un cuerpo terminado de principios, antes bien en el poder que el espíritu posee de extraer tales principios: una especie de impulso en una dirección siempre abierta, una exigencia que juzga lo que sobreviene, que lo evoca, pero que no lo contiene; porque la materia a la cual se aplica la razón constituyente, tiene su naturaleza propia y resistente, sus diversidades y sus rasgos intrínsecos.

Asimismo se puede distinguir entre una conciencia jurídica constituida y una conciencia jurídica constituyente. La conciencia jurídica constituida es el conjunto de los principios y de los hábitos dè pensamiento sobre el cual se regula en cada época, en cada sociedad dada, el movimiento del Derecho positivo. La conciencia jurídica constituida es una conciencia que varía a tenor de las sociedades, y que suele presentar variedades en cada una de ellas, y que suele, incluso, presentar en ciertos puntos op̃osiciones, cuando se comparan diversas sociedades. En cambio, la conciencia jurídica constituyente es la fuente primera, que hay que considerar como idéntica en cuanto a su fondo, si se quiere reconocer en los diversos Derechos positivos alguna analogía, suficiente para que sea legítimo compararlos entre sí y designárlos con un mismo vocablo.

Así pues, se tendria que distinguir también tres formas superpuestas de Derecho, de las cuales unas derivan de las otras por un proceso de encarnación gradual, proceso que implica toda una serie de grados intermedios. Esas tres formas son las siguientes:

A) Al nivel de la experiencia histórica y sociológica, los Derechos" positivos. 
B) Los Derechos ideales, que son las expresiones de la conciencia juridica constituida, los cuales constituyen conjuntos mejor o peor coordinados, y más o menos conscientes, de las finalidades cuya persecución preside la elaboración de los Derechos positivos: conjuntos todavía formulables, pero que se reducirían a principios generales y a reglas de pensamiento, capaces de orientar la obra del legislador y la labor del jurisconsulto.

C) Más allá de los Derechos ideales, los cuales parecen como expresiones más o menos aproximadas, pero nunca completas ni perfectas, se situaría el Derecho Natural, hogar de todo el pensamiento jurídico, alrededor del cual gravitaria todo el esfuerzo de la conciencia constituyente, pero que sería demasiado rico para poder ser expresado en conceptos definitivos, y que no podría ser alcanzado por ninguna observación, ni siquiera introspectiva, antes bien, que podría ser determinado tan sólo por la reflexión, valiéndose de una serie de recortes o abstracciones.

Husson expone después el segundo aspecto de la experiencia jurídica. Tal y como la experiencia juridica ha sido definida en su primer aspecto, en tanto que ensayo de un procedimiento, ella supone en el origen mismo de la tentativa, que constituye un núcleo, el sentimiento de un problema planteado por la vida social; y en su término implica la constatación de los resultados obtenidos. Pero adviértase que se trata de un problema práctico y no solamente teórico. La observación inicial no es simplemente la observación de un hecho: es, a la vez, el sentimiento de una necesidad o de una aspiración nacida en presencia de ese hecho, sentimiento que se traduce por un juicio de finalidad. Y la observación terminal puede servir de criterio nada más que en la medida en que ella envuelva una apreciación de resultados, que se expresa en un juicio de valor. En esos dos juicios, que en el fondo no son más que las dos manifestaciones sucesivas de una misma actividad, consiste la función de la conciencia jurídica, que se ejerce en ocasión de los hechos de la vida social, y que no se afirma netamente sino en contacto con estos hechos.

Los problemas jurídicos nacen de ciertos datos de hecho, que condicionan la solución de ellos. Así, los problemas complejos que plantea la organización de la familia proceden de la diferenciación de los sexos, de las tendencias que impulsan el uno hacia el otro, de las repercusiones, muy desigualmente repartidas entre hombre y mujer, que su acercamiento implica en sus almas lo mismo que en sus cuerpos, y de las condiciones que la naturaleza impone a la perpetuación de la especie humana y al crecimiento físico y moral de sus representantes. Se trata de datos que pertenecen al orden biológico, al psicológico y al social. Los reglamentos de policía y los procesos de responsabilidad a los que da lugar el uso de las carreteras han nacido del desarrollo de la circulación; han recibido su forma presente de la invención del automóvil, y están intimamente condicionados por el estado actual de la técnica de éste. 
"Ahora bien, Husson considera que la profunda originalidad de la experiencia jurídica, en contraste con la experiencia positiva, es decir, en contraste con la experiencia sensible de los meros hechos naturales, consiste en que mientras que en la segunda todo se reduce a la mera constatación material, por el contrario, la experiencia jurídica plantea problemas de conducta práctica y demanda una solución a esos problemas. $\mathrm{Y}$ añade que esos problemas reciben su sentido y su alcance precisamente por la intervención de un elemento moral, por virtud de la reacción de la conciencia común o de la conciencia del jurista, cuando éstas se enfrentan con tâles problemas."

Este elemento möral es esencialmente distinto de. los elementos positivos, cuyo sentido fija; pero no por eso se halla separado de ellos. La reacción moral no se produce originariamente, y no se experimenta sino al contacto y por el estímulo de los hechos: Un principio puede dejarnos fríos, - puede parecernos justo, en tanto que se le enuncia simplemente en términos abstractos. Un mero principio no nos conmueve, ni tampoco revela con claridad sus flaquezas, sino cuando lo captamos operando en los hechos concretos, pues entonces sus exigencias se hacen patentes a nuestra imaginación, y ponen ante ella con claridad las consecuencias a que ese principio da lugar. Cuando nos atrevemos a juzgar sobre un principio en términos meramente abstractos, es porque las nociones con las cuales opera, por ser= nos familiares, resumen todo un conjunto de experiencias anteriores. Por eso la discusión en términos abstractos no es plenamente accesible sino a aquéllos que están ya versados en la ciencia del Derecho. Por eso también las codificaciones han extraído siempre elementos de las costumbres, de las tradiciones, de las leyes anteriores, y de las autoridades del pretérito. Las grandes reformas hallan su principio en el movimiento de los hechos que suscita la necesidad de tales reformas. Hay una especie de intuición juridica, que se parece a la inducción socrática: parece que las exigencias de nuestra conciencia no se nos revelan sino en presencia de los hechos a los cuales ellas se aplican. Por eso Husson habla de interpretación del dato positivo y del dato normativo.

- Ahora bien, las exigencias de nuestra conciencia orientan el análisis dé esos hechos: en medio de la inmensa complejidad que esos hechoś presentan, son las exigencias de nuestra conciencia las que nos permiten extraer de ellos los elementos que debemos tomar en cuenta. Toda definición y toda administración del Derecho suponen una conceptualización del dato. Ahora bien, toda conceptualización implica una esquematización; y toda esquematización está orientada por una actitud intelectual, que, determinada primeramente por nuestros intereses, tiende, a medida que realizamos el esfuerzo de imparcialidad, característico del pensamiento jurídico, a inspirarse en nuestras reacciones y en nuestras aspiraciones morales.

$\therefore$ :

Toda realidad social hace intervenir la acción humana, que está influida 
por representaciones; y toda representación humana tiene por materia prima una percepción, pero implica una interpretación que, en el campo jurídico, está relacionada con un criterio moral. Por consiguiente, no son ni las ideas puras ni los hechos en bruto los que dirigen el mundo. Son los hechos en los cuales el instinto, el hábito, y la reflexión nos hacen captar la encarnación de las ideas, y las ideas que la tradición o el esfuerzo de nuestras voluntades logran encarnar en los hechos.

Así pues, este segundo aspecto de la experiencia jurídica es doble, tiene una doble dimensión, porque comprende la experiencia de hechos empapados ya por criterios éticos, a la vez que la experiencia de ideas normativas referidas a los hechos. De este modo, tal segundo aspecto de la experiencia jurídica, con las dos dimensiones mencionadas, no sólo es correlativo del primer aspecto, sino que, además, amplía éste $y$, al ampliarlo, abre a la investigación un dilatado campo.

Pasa después Husson a presentar y analizar otro aspecto de la experiencia jurídica. La distinción entre el fin y los medios rara vez se opera de modo preciso en el espíritu de los hombres, ni siquiera cuando éstos obran reflexivamente, como lo hacen de modo normal el juez y el legislador. Mucho menos cuando no obran reflexivamente. Generalmente el fin no es captado sino a través de los medios que concebimos para realizarlo. Así pues, la línea de demarcación entre el fin y los medios es flotante, ya que, toda acción humana apunta a una serie de resultados, de los cuales los unos están subordinados a los otros, de tal modo que el fin inmediato de las primeras etapas de esa serie teleológica constituye un medio en vista de fines ulteriores.

Asi, por ejemplo, esto se ve claro en el orden político: la democracia tal y como ha sido concebida desde fines del siglo xvil y durante el xix, y en el presente, ni es un simple fin, ni es un simple conjunto de medios: es todo un sistema complejo de medios, que por otra parte son variables en cuanto a los detalles, ordenados a un fin, a saber, la soberanía del pueblo; pero ésta aparece como el corolario y la condición del respeto debido a la persona humana, lo cual constituye el principio fundamental.

Ahora bien, toda experiencia implica una dualidad o incluso implica una especie de duelo entre el espiritu que ella instruye, o la voluntad que la persigue, por una parte, $y$, por otra parte, un dato que se impone al espiritu y a la voluntad, un dato que resiste a ambos, dato a cuyo dominio, espiritual o material, aspira la mente. Pero el dato no está constituido aquí simplemente por hechos que se imponen al hombre desde fuera y sin apelación; tampoco se limita a añadir los resultados anteriores de nuestra acción y a modificarse progresivamente bajo la influencia de esta acción. Además, el dato engloba también las aspiraciones que trabajan sobre nuestra voluntad y las convicciones que conquistan nuestra inteligencia. Esas aspiraciones y con- 
vicciones son susceptibles de ser transformadas por-la conciencia que adquirimos de ellas, y por la reflexión a la que las sometemos. Sin embargo, no somos capaces ni de suscitar tales aspiraciones y convicciones, ni de suprimirlas, ni de modelarlas de acuerdo con nuestro capricho. Es decir, los datos con que tropezamos tienen su fondo en la naturaleza, individual y social, de la especie humana; en esa naturaleza humana, la cual está inserta en la Naturaleza y condicionada por ésta. Se trata de una naturaleza viviente, en vía de desenvolverse y de evolucionar incesantemente, según una ley interna, que orienta sus cambios. El núcleo de la experiencia jurídica se encuentra, pues, más allá de los hechos mudables que son objeto de la observación biológica, psicológica y sociológica; se encuentra en una realidad más estable que ellos, de la cual esos hechos constituyen las expresiones complementarias. Se trata de la naturaleza humana en sus determinaciones primordiales, con sus propias condiciones de existencia y su dinamismo propio.

Es necesario buscar las raíces de la moral y del Derecho en nuestra naturaleza de seres vivos. Cuando en este sentido se habla de la naturaleza, no se concibe ésta como un simple efecto producido por el juego mecánico de fuerzas ciegas. Husson no rechàza esta idea puramente causal de la naturaleza; es más, la reconoce como legítima dentro de su propio dominio particular; pero considera que constituye una noción derivada e incompleta. Originariamente, la palabra naturaleza parece haber recibido su sentido de la observación de los seres vivos, que se desenvuelven espontáneamente siguiendo un tipo determinado. Por analogía con esos cuerpos vivos el pensamiento filosófico concibió después los cuerpos brutos y todo el conjunto de las cosas dadas a nuestra observación. El sentido de la palabra naturaleza expresó originariamente, según la fórmula de J. Lachelier, la idea de una existencia que se produce, o que por lo menos se determina ella misma, en todo o en parte, sin necesitar una causa extraña; por consiguiente, se trata de la idea de un principio interno de determinación, que da cuenta a la vez de la estructura del ser y de su comportamiento. Si tal principio designa igualmente esta estructura, considerada en sus detalles, y este comportamiento, analizado en el desarrollo de sus procesos, tal cosa sucede por extensión, porque esa estructura y esos procesos expresan la esencia profunda del ser, la cual reside en la idea que coordina la estructura y que dirige los procesos. Husson se refiere a Aristóteles, quien extrajo esta noción con gran vigor y se esforzó en darle una interpretación metafísica. No hay que reprochar a la ciencia moderna que haya abandonado esa noción para estudiar mejor la estructura y los detalles del universo material. Pero la ciencia moderna ha cedido a una especie de deformación profesional, al dedicarse al estudio del hombre. dentro de dificultades inextricables, cuando pretendió imponer a la biología las mismas limitaciones de perspectiva que a la física, y condenar tachándola de prejuicio aquella primera comprensión más amplia de la naturaleza. La 
biología en sus trabajos cotidianos puede hacer a un lado la idea de un poder productor, cuya acción se traduce por la sucesión ordenada de los fenómenos; pero no debe olvidar que esa idea está implicada inevitablemente por su objeto. Los espíritus más empeñados en rechazar como antropomórfica la concepción teísta, que refiere la naturaleza a un Dios trascendente, no hacen más que sustituir esa idea, consciente o inconscientemente, por la de una fuerza oscura y anónima inmanente a todas las cosas. Es necesario reconocer francamente la especificidad de las ciencias bịológicas y la del orden humano. Es necesario comprender que las ciencias biológicas y las ciencias de lo humano no pueden atenerse a la noción totalmente exterior de la naturaleza, la cual es suficiente para el estudio del mundo inerte. Sin embargo, por otra parte, ese orden inerte, con el advenimiento de la reflexión, manifiesta abier-' tamente y transpone en términos intelectuales lo que en el estudio de la planta y del animal está inscrito como en filigrana.

En efecto, la esencia de un ser, si esta expresión tiene sentido, no puede reducirse al conjunto de las propiedades que la observación descubre en él, y de los fenómenos cuya sede él es. La esencia de un ser debe residir en el principio que hace la unidad de todas esas propiedades, y proporciona la clave de todos los fenómenos, es decir, debe residir en la idea en la cual esas propiedades se coordinan. Ahora bien, este principio y esta idea, inaccesibles al fisico, se imponen al biólogo. Este principio y esta idea implican la ordenación de las partes o de los elementos en función del conjunto, y la ordenación de los procesos, en función del término hacia el cual éstos se encaminan. Es así como se define la idea de finalidad, si se la despoja de sus determinaciones humanas. Ahora bien, esta ordenación, que en la planta e incluso en el animal es simplemente padecida y vivida, es susceptible en el hombre de reflejarse en el pensamiento y de convertirse en objeto de consentimiento. Es más, esa ordenación en el hombre no puede realizarse sino mediante él, es decir, mediante el juego de su inteligencia y de su voluntad, mediante iniciativas contingentes por las cuales él participa, aunque desde lejos, en la obra creadora. Esa ordenación implica una vocación de rebasarse o trascenderse a sí misma, incluso quizá una aptitud para recibir un don divino que, si adviene, la transfigurará. Es esta ordenación, esta vocación, esta aptitud, lo que hace surgir el orden de los valores del orden de los hechos, sin reducir aquél a éste, porque, si bien el orden de los valores se halla contenido virtualmente en el orden de los hechos, sin embargo, no procede de éste, antes bien, deriva de una fuente más alta, que es la fuente de la vida: las normas por referencia a las cuales se definen los valores son la expresión de los fines en los que se encuentra la explicación de los hechos.

El hombre, que no es el autor de su naturaleza, no puede elegir sus fines: esos fines se le imponen; y a él le queda tan sólo la alternativa de comprenderlos y adaptarse a ellos para su máximo desarrollo, o, por el con- 
trario, desconocerlos y rehusarse a cumplirlos, con el consiguiente detrimento propio.

El Derecho, en la esfera de las relaciones organizadas que constituye la vida social -así como la moral, cuya esfera se extiende a toda actividad humana-, no es sino la expresión de esa obligación, que se funda en la Voluntad Creadora; pero que asocia a ésta las voluntades humanas. Por eso, el Derécho es a la vez dado y construido - conștruido sobre un dato-, variable en, sus modalidades, $y$, sin embargo, constante en sus objetivos primordiales.

La razón del Derecho, como también la de la moral, consiste en que el hombre no solamente tiene un destino, que sería el simple resultado de un concurso de fuerzas ciegas, sino también una destinación, una misión, en la que se manifiesta una ordenación inteligente. $Y$ sería incluso mejor hablar de una vocación, de la cual puede tomar conciencia más o menos claramente, y a la cual puede ser infiel; pero cuya llamada es lo único susceptible de dar un sentido a su vida, y de asegurar el equilibrio de ésta. E1 Derecho, al igual que todas las realidades en cuya elaboración participa la voluntad humana, se halla expuesto a múltiples falsificaciones, y está siempre mezclado con elementos impuros; pero, referido a su esencia, que se define por su función en la cual se funda su autoridad, no es otra cosa que el arreglo más o menos juicioso de la vida social por las actividades de los hombres, según las exigencias de su destinación, misión o vocación.

El Derecho tiene por materia las tendencias humanas, y las presiones que los individuos sufren, en razón de esas tendencias, por parte de sus semejantes y de las asociaciones en las cuales éstos se agrupan. Todo derecho individual implica un interés, del cual constituye la protección. Todo interés implica una necesidad o una aspiración, de la cual constituye la expresión. La tendencia se traduce con respecto a otro o a la colectividad por una reivindicación. Y la protección que esa tendencia recibe, se traduce en un deber, que es el correlativo necesario del derecho. Pero, el Derecho no se reduce a la garantía de los derechos subjetivos individuales: abarca también todas las demás obligaciones que la sociedad nos impone bajo la sanción de una coerción eventual.

Ahora bien, todas las obligaciones jurídicas no se agotan en el conjunto de los deberes de mero respeto al derecho ajeno. El orden social no se reduce a una simple coordinación de las libertades e intereses privados. Pero, muchísimo menos, podemos admitir la tesis opuesta, la tesis de que los derechos subjetivos sean una simple concesión de la sociedad. Es decir, Husson rechaza el individualismo al cien por ciento; pero repudia también, de modo terminante, categórico, definitivo, el principio colcctivista.

El psicólogo y el sociólogo, e incluso el biólogo, pero sobre todo el filósofo, tratan de descubrir en la realidad humana las condiciones y el modo de aparición de las normas jurídicas. Al iniciar esta empresa se encuentran 
en presencia de un ser que es a la vez individual y social, animado de tendencias egoistas que le impulsan a buscar su bien en la apropiación de los recursos exteriores, y de tendencias ideales que lo invitan a subordinarse a fines más altos; de un ser que además está inserto también en grupos a los cuales se adhiere espontáneamente o por la fuerza de las cosas, y cuya presión se inscribe en su naturaleza en forma de hábitos.

El Derecho tiene como objeto la salvaguardia de esos intereses individuales y a la vez la protección del interés. söcial. Pero la palabra interés presenta un doble sentido: designa subjetivamente aquello que mueve espontáneamente nuestra vida, y objetivamente aquello que se revela como efectivamente ventajoso, a la luz de un estudio imparcial.

\section{La idea de la justicia}

Lo que especifica el Derecho, es que él tiene en cuenta los intereses de los diferentes individuos y los de los grupos sociales, y que su misión consiste en establecer entre ellos una especie de modus vivendi. Precisamente en este punto aparece la noción de la justicia, y se ve claramente por qué el Derecho, incluso cuando se refiera a la autoridad social, está dominado por esta noción, puesto que la utilidad social no debe hacer desaparecer la protección de los intereses individuales, ni de los intereses de los grupos sociales más pequeños, sino en la medida en que se acepte someter todos esos intereses a una regla común que los limite. Pero la noción de justicia es compleja, y ella no se basta a sí misma. La noción de justicia no se reduce a la noción de aquilibrio, antes bien, implica al mismo tiempo, como un elemento tan fundamental como éste, la noción de lo mío, de lo tuyo - y de lo suyo. Además, la noción. de justicia se especifica de dos maneras muy diferentes según que se considere las simples relaciones de contacto y de cambio, o la cooperación por la cual se define la asociación. Ahora bien, esas nociones, la de equilibrio y la de lo mío, lo tuyo o lo suyo, pueden ser consideradas como datos últimos, solamente por el moralista o por el jurista que realizan una labor práctica en una sociedad en la cual las convicciones morales y políticas son relativamente homogéneas.

Hay que observar, ante todo, que el equilibrio no es necesariamente la igualdad, por la cual suele definirse comúnmente la justicia conmutativa, ni tampoco la proporcionalidad. La justicia plantea una serie de temas en varios planos, en varios supuestos, por así decirlo, jerarquizados.

Por de pronto, la justicia implica y requiere un ajuste de las pretensiones rivales. Ahora bien, ese ajuste puede ser obtenido mediante la preponderancia de algunas de esas pretensiones sobre otras. La afirmación de una igualdad de naturaleza no excluye una desigualdad de condición. El problema consiste en averiguar cuáles sean las desigualdades de las que se deba tomar 
cuenta y razón. En esta tarea es necesario proceder mediante el análisis a través de varios planos sucesivos del pensamiento.

El primer plano está formado por el terreno de la composición, terreno sobre el cual los egoísmos, forzados a tener que contar los unos con los otros, o juzgando que asegurar la paz al precio de algunas concesiones es más ventajoso que correr los riesgos de una lucha, recurren explícita o tácitamente a un compromiso o a un arbitraje (ideas destacadas por Hobbes y Rousseau). A este nivel, la igualdad sería tan sólo un medio, aceptado por las partes en presencia o adoptado por el árbitro, para obtener más fácilmente el consentimiento o la sumisión de todos los interesados, concediendo a cada uno de ellos el máximo y exigiendo a cada uno de ellos un mínimo. Sucede empero, que para que este equilibrió tenga éxito, será necesario hacer intervenir otro factor: un cierto sentido de la equidad, que implica alguna comprensión de los intereses y de las reacciones del adversario. Pero este sentido de la equidad lo encontramos tan sólo elevándonos a un plano superior.

Este sentido de la equidad implica una dimensión racional. Se entiende la equidad, al modo kantiano, como la facultad de pensar las cosas desde un punto de vista impersonal y universal, refiriéndolas a leyes generales; $y$, por consiguiente, se puede considerar el sentido de la justicia como un sentido racional, como una pauta de imparcialidad.

Ahora bien, incluso desde el punto de vista impersonal, que es el punto de vista de la razón, la igualdad o la proporcionalidad, por las cuales se define la justicia, no podrán imponerse sino en la medida en que establezcamos previamente que los hombres son efectivamente iguales. Indudablemente es verdad que los hombres, cualquiera que sea la desigualdad de sus convicciones, son iguales moralmente en el sentido de que, perteneciendo a una misma especie, poseen una misma naturaleza, y que esta naturaleza, que se define por la razón y que nos hace capaces de moralidad, posee ella misma un valor eminente o una dignidad, que no existe en las especies animales.

Ahora bien, la identidad de naturaleza sólo puede convertirse en una razón suficiente para respetar a los otros hombres, si éstos cesan de ser considerados como extraños, es decir, si se les ve como semejantes, como prójimos. Esto es, es necesario que uno vea a los demás hombres como seres que participan de la misma condición y, como seres a los que uno está asociado recíprocamente en cuanto al propio destino de todos. La dignidad de la persona racional no puede crear derechos para ésta cuando la razón y la moralidad no residen aún efectivamente en ella —como sucede con el niño-, o cuando constituyen meras virtualidades -como en el caso del hombre perverso o del loco. La dignidad de la persona racional en esos casos puede crear. derechos para ésta, tan sólo si implica reconocer en las demás personas, incluso en las mencionadas, una vocación esencial, pareja a la nuestra y estre- 
chamente ligada a ella. Se debe reconocer que los hombres son solidarios los unos de los otros, porque su vitalidad se mide por su amor; y porque su destino, aunque éste sea individual, consiste en llegar al disfrute de bienes que no pueden adquirir sino mediante la cooperación social.

Cierto que indudablemente la justicia y la caridad son ideas muy diferentes; sin embargo, la justicia no se explica plenamente sino por la caridad; y es en ésta en la que la justicia halla su fundamento inquebrantable. En verdad la justicia se distingue netamente de la caridad, porque la justicia apunta a establecer un reparto, mientras que la caridad, por el contrario, tiende a la comunidad. Sin embargo, a pesar de esta diferencia indudable, la justicia es a la vez el corolario y la condición de la caridad. La justicia trata a los hombres como seres irreductibles los unos a los otros, cada uno de los cuales posee lo suyo propio, y cuyos intereses están en concurrencia, por lo cual deben ser ajustados entre ellos. La justicia implica la idea de alteridad. Asi pues, ella por sí misma puede crear tan sólo un orden exterior, mensurable desde el punto de vista cuantitativo, que consagre y consolide los egoísmos. Por el contrario, la caridad aspira a la unión, incluso a la unidad; y por ello establece entre los hombres un vínculo espiritual que suprime o disminuye todas las barreras entre ellos. Se trata de individuos distintos, sujetos a buscar su subsistencia y las condiciones para su desarrollo en bienes materiales cuyo uso implica la apropiación de éstos. Por eso, no pueden realizar entre ellos una cooperación, sino en la medida en que comiencen por establecer entre sus intereses particulares un equilibrio que elimine las divisiones, que asegure a todos una parte de bienes, y que fije a cada uno su papel en la acción común. Así pues, la caridad puede establecerse tan sólo sobre una base de justicia. Sin embargo, por otra parte, un equilibrio tal puede ser impuesto estrictamente tan sólo a seres que aspiren a una cooperación, e incluso a una comunión, o que por lo menos tengan esa vocación. Pues el ajuste de los intereses puede establecerse bastante bien por la subordinación de los unos a los otros, péro cobra la forma de la igualdad sólo en la medida en que los seres humanos adquieren conciencia de su unidad. Para que la justicia se convirtiera en universal fue necesario que el Cristianismo llamase a todos los hombres a una misma vida espiritual.

La justicia se impone al hombre, sólo porque el destino humano no consiste en la expansión, siempre precaria, de la vida sensible, sino en la participación en una vida espiritual, que implica el amor mutuo y que no puede realizarse más que en éste; es decir, porque, como lo enseña el Cristianismo, el mundo tiene su causa y su fin último en un Ser que es esencialmente amor, y que no lo ha creado sino para asociar a los demás seres a su beatitud.

Todos esos caracteres de la justicia, considerada ésta en general, destacan con un relieve mucho mayor al estudiar especialmente la justicia social. Pues la justicia social no se limita a imponernos cargas y a reconocernos 
ventajas como contrapartidas las unas de las otras; nos impone además participar en las sociedades naturales - la familia, la profesión, la asociación política; y a las asociaciones políticas les impone el participar en la comunidad de las naciones. Así pues; la justicia social expresa la solidaridad humana mucho más directamente que la justicia conmutativa. La justicia social se basa en el hecho de que en todos los fines humanos hay implicados fines sociales: el hombre puede desenvolverse material y moralmente tan sólo en comunidad con los otros hombres. Es precisamente por la justicia social que la justicia conmutativa se liga a la caridad. La idea de la vinculación de nuestros destinos debe añadirse a la idea de la identidad de la naturaleza humana, para obligarnos a tomar en consideración los intereses de nuestros iguales. La justicia social incorpora algunas dimensiones de la caridad: el bien común a cuya realización debemos contribuir, y el cual exige que los más favorecidos por el talento, por la suerte, o por las múltiples diferenciaciones que implica toda división del trabajo, no usen sus ventajas en detrimento de sus asociados, sino, por el contrario, que las hagan repercutir beneficiosamente sobre éstos.

Ahora bien, la noción de lo mío, de lo tuyo, de lo suyo, conduce a constataciones convergentes. Hay una reivindicación en germen en cada una de nuestras tendencias. Ahora bien, la justicia implica una criba que lleva a cabo una selección entre esas reivindicaciones, a fin de discernir aquéllas cuya satisfacción debe imponerse a otro, de aquéllas que no merecen la protección de la ley ética ni de la autoridad social. Ahora bien, todas esas reivindicacionés no presentan para nosotros, ni subjetiva ni objetivamente, un interés igual. Por eso, la justicia supone además una apreciación que determina el valor respectivo de esas reivindicaciones. Supone, por tanto, criterios que trascienden la experiencia positiva, y que encuentran su justificación última tan sólo en nuestro destino.

Desde el punto de vista de la observación positiva se puede distinguir lo que es parte integrante de nuestra persona (como nuestra conformación física o mental), lo que emana de nuestra persona (como nuestros actos y nuestras obras), y lo que la persona recibe de su medio material y social ambiente. Asimismo se puede determinar, en el interior de cada una de esas categorias, los grados en la dependencia o en la posesión: hay piezas de nuestra estructura mental, como de nuestro organismo, que son más esenciales que otras; hay manifestaciones o efectos de nuestra actividad en que ponemos más de nosotros mismos; hay bienes que nos son más necesarios o que nos apropiamos de un modo más completo; etc. Pero dentro de esas diferentes categorias la demarcación es flotante. $O$ mejor dicho, cada una de esas categorias puede ser constituida sólo por una abstracción que considere aisladamente elementos que en lo concreto son inseparables: nuestro temperamento y nuestro carácter, nuestro vigor físico o moral, incluso, hasta cierto 
punto, la conformación de nuestro cuerpo y las caracteristicas de nuestra alma que no están por completo determinadas desde nuestro nacimiento -antes bien que reciben la impronta de nuestra conducta y de influencias de todas clases que sufrimos a través de nuestra educación y a través de nuestra existencia adulta. No hay ninguna de nuestras actividades que pueda ejercerse sin emplear recursos exteriores, ni que pueda aportar frutos sin apoyarse en la cooperación de nuestros contemporáneos, $o$ en la herencia de las generaciones anteriores. Además, los bienes que la naturaleza pone a nuestra disposición, en su mayor parte no están repartidos por ella entre los individuos; se ofrecen a todos, y van a parar a aquél que se apodera de ellos, si la autoridad social o el acuerdo de los intereses no intervienen para regular la devolución. Por otra parte, cualesquiera que sean la naturaleza y la solidez del vínculo que de hecho nos liga con cada una de esas cosas, la existencia de ese vínculo puede constituir un título legítimamente fundado o justificativo tan sólo en función de un criterio valorador.

Por mucho que se busque, la única razón para conseguir esta legitimación será la existencia de un destino individual, que dependerá de los dones recibidos por cada uno y del partido que de ellos haya sacado para su conducta. Pero, bien entendido, se trata de un destino al cual los destinos de nuestros semejantes se hallan ligados, de tal modo que cada uno entre nosotros no puede alcanzar el suyo con detrimento del de otro. Cierto que es primordial, capitalisimo, el respeto a la persona humana, el reconocer que ésta no debe jamás ser tratada como un simple instrumento o como un mero medio, antes bien, que constituye un fin en sí; pero este fin no puede imponerse a los hombres sino en la medida en que cada uno de ellos se encuentre interesado en el mismo; y no pueden estar interesados sino en la medida en que exista una comunidad humana, la cual se manifiesta ya en el plano intelectual por la identidad de la razón, y en el plano material por la solidaridad, y que obtiene sólo su sentido cuando se cumple en una comunión espiritual. Pues todo lo que la experiencia positiva puede revelarnos a este respecto es que ninguno de nosotros puede desenvolverse sin contar con todo eso. Pero queda por establecer que hay el derecho de obtener el consentimiento $y$, si fuese necesario, el socorro de los semejantes, para este desarrollo. Ahora bien, esto requiere la vinculación de los destinos individuales. Sin esa vinculación uno se encontraría colocado simplemente bajo un régimen de concurrencia, en el cual el más fuerte o el más hábil aplastaria al otro, y podría incluso pretender justificarse intelectualmente refiriéndose a lo que el animal hace sin preocuparse de argumentos, alegando que su poder lo convierte en más digno de desenvolverse, porque es capaz de realizar un tipo superior de humanidad.

A fin de dosificar el valor de cada uno de los intereses, para decidir cuáles deberán ser reconocidos como inviolables, y cuáles, en caso de conflicto. 
deberán ceder a otros, es fácil constatar que esto no lo podemos llevar a cabo estableciendo simplemente que el hombre tiene un destino. Nos es indispensable además precisar cuál sea ese destino, o, por lo menos, debemos fijar las exigencias inmediatas por las cuales ese destino se traduce prácticamente.

Si nuestro destino consisticse exclusivamente en el disfrute de los bienes materiales, entonces no se podría a pretexto del interés de otro, ni siquiera del interés de la colectividad entera, imponer a un hombre el sacrificio de su fortuna, de su bienestar, de su vida. $Y$, sin embargo, ninguna sociedad puede subsistir y asegurar la vida de sus miembros, sin pedir a veces estos sacrificios o algunos de ellos. En esto hallamos el signo de que el destino humano se encuentra en otra parte, se encuentra en la adquisición de bienes espirituales, cuya persecución está sin duda condicionada por bienes materiales, e implica la salvaguarda de éstos en una gran médida, pero que los trasciende o rebasa, y puede incluso, en determinado momento, no conseguirse sino a costa de una renuncia. Hay razones de vivir que valen más que la vida misma, o por lo menos más que la vida terrestre, pues el problema que se plantea al metafísico es precisamente saber si esto es asi porque a tales razones de vivir está ligada una vida más alta, que se prolonga más allá de la tumba.

\section{La determinación de la materia por la forma se expresa por una norma que} es una idea

Los conceptos juridicos surgen de la experiencia positiva, desde el instante en que ésta es interpretada en función de las exigencias de nuestro destino. Tales exigencias las percibimos por virtud de la intelectualización de nuestras tendencias, la cual constituye nuestra conciencia moral.

Husson sostiene que puede haber experiencia de una norma. En el fondo, la experiencia de una norma no es de naturaleza diferente que la experiencia de un hecho, si bien aquélla se refiera a un objeto esencialmente diferente.

Toda percepción humana implica conceptos. Un objeto o un hecho no reviste individualidad para nuestro espíritu y no es penetrable por éste, sino en la medida en la que los diferentes datos sensibles son coordinados entre sí, por un principio que da cuenta de su acercamiento o de su vinculación, confiriéndoles un sentido. Tal cosa resulta manifiesta para los hechos científicos, que se constituyen por el espíritu mediante una interpretación delicada. Pero lo mismo se verifica igualmente respecto de los hechos en bruto. La única diferencia consiste en que el hecho en bruto se halla constituido por una actividad espontánea, que realiza la incorporación del concepto a los datos sensibles. En verdad, entre los hechos y las ideas no existe la oposición tajante que solemos establecer muchas veces. Todo conocimiento humano 
consiste en la interpretación de datos sensibles. Entre las concepciones metafísicas y los hechos en bruto hay toda una serie de grados intermedios, de los cuales los más salientes son los hechos científicos. Así pues, en un sen. tido, que no tiene en absoluto nada de empirismo, Husson sostiene que todo conocimiento humano es una experiencia.

Ahora bien, si la idea es esencialmente una visión sintética de la cosa, el plan que rige la estructura de ésta -0 , si se prefiere decirlo en lenguaje aristotélico, la forma que gobierna todas las determinaciones de la cosa-, la idea puede, además, expresar lo mismo el fin de la cosa que su estado actual. Mejor dicho: la idea expresa el estado actual de una cosa, sólo en la medida en que se trata de una cosa ya realizada, ya determinada, lo cual en nuestra experiencia sucede sólo con los objetos inertes. Pero además la idea, siempre que se trate de un ser en devenir, cuyo desarrollo se orienta hacia un fin, y - no reviste sentido sino en relación con ese fin, será necesariamente la expresión de tal finalidad, el designio de la cosa, o del movimiento. En este caso, la experiencia, entendida como el conjunto de operaciones intelectuales mediante las cuales el espíritu organiza el dato, podrá constituirse sólo extrayendo de ese dato una norma. La norma no es más que la idea o la esencia de un ser o de un acontecimiento que se encamina hacia un fin aún no alcanzado. En cambio, la ley cientifica es la idea de un objeto o de un acontecimiento cuya naturaleza está plenamente realizada.

Después' de haber puesto en claro lo que antecede, Husson considera que el problema del método de las ciencias normativas ya no ofrece dificultad. El método de las ciencias normativas tiene su clave en la teoría y en la crítica del instrumento conceptual que nuestra inteligencia necesita emplear para captar la idea. Sólo que aquí el concepto que sirve de regla para nuestra actividad, al mismo tiempo que de cuadro para nuestro conocimiento -puesto que la idea que expresa es la de un fin-, se inserta en alguna medida en el dato que polariza.

\section{Distinción entre la idea y los conceptos}

La idea de una cosa, de un ser, de un acontecimiento o de un acto, no es una simple representación mental, más o menos relativa al espíritu que la piensa. Se debe entender la idea, de acuerdo con la vigorosa acepción que el platonismo exaltó, que fue conservada por la Edad Media, y a la cual los mismos científicos modernos han tenido que recurrir de nuevo - por ejemplo Claude Bernard, cuando definió la vida por la idea directriz de la evolución vital. De acuerdo con esto, la idea es la esencia de esa cosa, de ese ser, de ese acontecimiento o de ese acto; y es lo que constituye su inteligibilidad. Así pues, la idea es lo qué contiene la razón de todos los caracteres de su objeto y de todos sus desarrollos esenciales. Por consiguiente, 
la idea, por así decirlo, recoge y compendia la diversidad de los caracteres en un todo, perfectamente uno y, sin embargo, muy rico. Claro que una visión tal excede la capacidad de la inteligencia humana. Lo más a lo que la inteligencia humana puede llegar, en instantes de iluminación, cuya frecuencia y cuya claridad y alcance excepcionales constituyen el genio, es a entrever las líneas directrices como en una especie de visión de relámpago. Después, tiene que reconstruir el objeto pieza por pieza, fijándose sucesivamente en los diferentes aspectos que la experiencia sensible le presenta, o que el razonamiento le descubre, acercando y relacionando esos aspectos unos con otros, para hacerlos entrar en sintesis más y más vastas. Se trata de algo así como las peripecias de un drama, o como las ruedas de una máquina, que están comprendidas dentro de la concepción que de ellas tuvo el autor o el inventor, las cuales pueden ser entrevistas por éste en una intuición, pero que después no van haciéndose presentes sino de un modo lento, a costa de una labor a menudo penosa, que debe vencer múltiples resistencias. Ahora bien, puesto que la realidad concreta es de una riqueza inagotable, nuestro pensamiento no logrará nunca reconstituirla de una manera integral. Necesitará completarla sin cesar, complicarla o retocarla, para hacer sus esbozos más fieles, aunque jamás llegue a concluir enteramente su tarea.

Esas vistas parciales que adquirimos sobre la idea, y por cuya combinación intentamos imitarla, son lo que el lenguaje técnico y la filosofía llaman "conceptos".

El Derecho positivo se nos presenta bajo la forma de un sistema de reglas conceptuales: nace sólo en el momento en el que las obligaciones que se imponen en la vida social son traducidas a reglas intelectualmente formulables, que ajustan los intereses, públicos y privados, coordinando las conductas individuales y colectivas. Esas obligaciones pueden tomar cuerpo sólo mediante tales reglas. Pero esas reglas expresan el Derecho tan sólo imperfectamente, y están expuestas siempre a traicionarlo, por causa de la índole general y analítica del pensamiento conceptual y discursivo.

Las categorías jurídicas, al igual que todas las categorías lógicas, son siempre tan sólo cuadros imperfectos, susceptibles de abrirse a actos o a situaciones para los cuales no han sido hechos o, por el contrario, a excluir actos o situaciones a los cuales deberían convenir.

El jurista está condenado a navegar incesantemente entre varios escollos. $\mathrm{O}$ bien el jurista se contentará usando términos del lenguaje cotidiano, y dejando al uso y a los intérpretes el cuidado de fijar el sentido de esos términos; o bien, se esforzará en fijar criterios precisos, pero en este caso desembocará generalmente en el resultado de restringir la aplicación de sus textos dentro de límites tan angostos, que aquellos no bastarán para responder a las necesidades de la práctica. O bien, el jurista, renunciando a las fórmulas generales, multiplicará las hipótesis a fin de enumerar el mayor número 
posible de especificaciones; pero no conseguirá jamás agotarlas todas, de manera que, en presencia de aquéllas que olvidó prever, no tendrá más remedio que recurrir a las analogías y a las ficciones.

Cualquiera que sea el partido que el jurista tome, le resultará imposible encerrar el Derecho dentro del cuadro de un código o de una teoria. Necesitará abandonar el Derecho a la adaptación de los intérpretes, quienes' tendrán un poder discrecional más o menos amplio.

Esa interpretación, sea doctrinál o jurisprudencial; nunca podrá proceder por vias puramente lógicas. Por el contrario, inevitablemente tendrá que precisar sus inducciones y tendrá que desviar sus deducciones mediante la introducción de elementos de fondo, extraños a la fórmula inicial. Esos elementos de fondo le serán impuestos a su espíritu por la experiencia de los hechos y por las reacciones morales que éstos suscitan. Ante nuevos tipos de situaciones de hecho, los tribunales, los autores y el legislador mismo, tienen que emanciparse de los cuadros que habían usado anteriormente; se ven obligados a restringir o a repudiar los criterios que antes habían adoptado. Esto muestra la inadecuación de nuestras nociones y de nuestras fórmulas jurídicas a las ideas que aquéllas intentan traducir. Los autores de esos conceptos los habían enunciado sin ponerles limitaciones, como si se tratase de la razón general, de la cual se podría desprender la solución para todos los casos particulares. Pero la cosa no es así.

Nuestros'concèptos implican una esquematización de las ideas. Pero esas ideas, en el dominio del Derecho, son diferentes de las ideas en el campo de la biología; pues las ideas en el sector del Derecho no definen tipos cerrados.

Todos los conceptos y todas las proposiciones en que se formula el Derecho no revisten su sentido exacto y su alcance, sino cuando se ponen en relación reciproca. Esos conceptos y esas ideas son como las palabras de una misma frase, o, en términos más generales, como el conjunto de los signos que constituyen un mismo idioma, o incluso se podría decir como las tintas y matices de un mismo cuadro, cuyos valores dependen de los matices o signos concomitantes. La cosa es clara al nivel de los principios más generales; la justicia se puede definir y se puede sacar de ella sus exigencias, tan sólo considerándola a la vez bajo los dos puntos de vista complementarios de lo mío, de lo tuyo, de lo suyo, y del equilibrio. Una teoría jurídica, al igual que una ley o una costumbre, implica una compensación de reglas, cuyo conjunto puede realizar un orden satisfactorio para nuestro sentido de la equidad, aunque cada regla, tomada por separado, se preste a objeciones, o conduzca a consecuencias inadmisibles.

\section{ro. Influencia de la práctica}

No se debe olvidar jamás que los conceptos jurídicos, y las proposiciones 
que éstos suministran, ofrecen los términos que sirven para regular la acción y a la vez para presentar realidades preexistentes, así como tamibién para definir los medios de esta acción y, al mismo tiempo, para designar los fines de ella. Està constatación produce consecuencias múltiples y diversas.

Muchos conceptos jurídicos implican una gran parte de artificio, porque tienen por objeto las construcciones más o menos ingeniosas que el legislador o el jurista elaboran para realizar su ideal en los hechos. Así pues, muchísimos de esos conceptos no representan la realidad de un modo exacto ni adecuado. Incesantemente se muestran como deficientes por virtud de la complejidad y de los cambios de los actos o de las situaciones. Así, sucede que las voluntades humanas imaginan una y otra vez soluciones nuevas, que escapan a los cuadros de esos conceptos o que quebrantan sus perfiles.

El Derecho positivo aparece, en la estructura que le dan el legislador y la costumbre, así como en el uso que de él hacen los interesados, como un sistema de medios ordenados a la realización de ciertos fines. Pero, como ya se ha dicho, a veces es difícil distinguir entre los medios y los fines, porque muchos fines representan sólo escalones intermedios, es decir, constituyen medios para el cumplimiento de fines ulteriores. Los textos legales, las costumbres, las reglas consagradas por la jurisprudencia, las soluciones preconizadas por los autores, son para los alegantes, para las partes en litigio y sus consejeros, sólo "medios" para llegar a sus fines. El juez mismo, muchas veces para apreciar un acto, para enfocarlo en sus consecuencias y en sus intenciones, encuentra dificultades. Por otra parte, la intención para el jurista es algo diferente de lo que ésta significa para el psicólogo. La intención es enfocada por el psicólogo desde el punto de vista subjetivo. En cambio, el jurista tiende a determinar el valor del acto sobre todo desde el punto de vista del resultado objetivo, desde el punto de vista de su repercusión efectiva sobre los intereses de otro y sobre la vida social. Para el jurista, el problema consiste en atender a las exigencias del equilibrio social. Sin embargo, esta labor no puede ser nunca cumplida de un modo definitivo y rigoroso. Sus resultados, por muy ajustados que resulten, se prestan siempre a una explotación más o menos interesada; por lo cual es indispensable velar incesantemente para prevenir los abusos y, si fuese necesario, para enderezar los entuertos.

De hecho, sucede también que a veces las intenciones del legislador o del juez no son forzosamente de una rectitud perfecta; porque pueden ser victimas de prejuicios; o pueden dejar corromper en ellos el sentido de la justicia y del interés general, e incluso perseguir cínicamente fines que son extraños a estos valores. Una vez más, paréceme oportuno llamar la atención del lector sobre una concordancia, en este punto, entre las observaciones de Husson y las de los realistas norteamericanos.

El Derecho positivo se encuentra ante un gran escollo. El Derecho positivo puede adquirir vida sólo encarnándose en un sistema complejo de nocio- 
nes y de reglas, que pueden siempre ser desviadas de su destino, o arregladas en vista de fines por entero diferentes. En la práctica no es posible remitirse sin garantías ni a la apreciación de los sujetos del Derecho ni a la de sus agentes. Esto podría dejar el campo libre a la anarquía; o podría también abrir la puerta a todas las arbitrariedades. La vida social supone una disciplina común. Pero la autoridad de aquéllos que regulan esta disciplina no implicaría freno ninguno, si esa autoridad dispusiera de un ilimitado poder discrecional para plegar las reglas a su sentimiento. Lo más que cabe hacer es elegir tan juiciosa y prudentemente como se pueda a aquéllos que han de asumir la pesada carga de formular y aplicar las reglas de Derecho, y de formarlos y educarlos del modo más cuidadoso que resulte factible. Asimismo, conviene multiplicar el número de esos funcionarios y dividir sus poderes de suerte que se establezca entre ellos un control y una corrección mutuos. Conviene asimismo instituir procedimientos que los obliguen a ponderar sus decisiones, y que permitan revisarlas en caso necesario.

Así pues, el jurista se ve forzado a encajar el Derecho dentro de mecanismos lógicos y dentro de procedimientos que cumplen una función reguladora, pero que se desenvuelven a ciegas cuando se les abandona a su propio movimiento y oponen una cierta fuerza de inercia a los impulsos de la conciencia, y pueden ser puestos torcidamente al servicio de la voluntad de individuos o de grupos.

Ahora bien, como el papel del jurista es el de construir, mantener y manipular los mecanismos cuyo funcionamiento asegurará la realización de los fines de la vida social, el jurista está siempre expuesto, por causa de una deformación profesional, a llevar a su atención hacia la perfección intrínseca de esos mecanismos - hacia su precisión, hacia su eficacia, hacia su comodidad, hacia su adaptación exacta-, más que hacia la naturaleza y hacia la legitimidad de los fines. Es más, el jurista, por causa de su tendencia al virtuosismo, puede dejarse llevar, por un defecto de carácter, o incluso simplemente por una modestia mal comprendida, a desinteresarse respecto de los fines, para concentrar toda su atención en el ajuste de los medios. Cuando sucede esto, el Derecho se convierte en el arte de dar a las reivindicaciones de los individuos o a la voluntad de los poderosos formas exteriores que aseguren su triunfo fácilmente. Y esto sucede ligando falazmente las conciencias mediante un conjunto de procedimientos que dan a tal acción la apariencia de legitimidad, sin importar que el fondo realmente perseguido naufrague, siempre y cuando la forma quede a salvo.

$Y$ puede suceder que incluso cuando ese espíritu jurídico deformado no llegue hasta el punto de disfrazar la injusticia, por lo menos oponga una cierta resistencia a los progresos de la justicia, en la medida en que asocie a la realización de ésta -que siempre es sólo parcial- la satisfacción de intereses menos respetables. 
Sin embargo, constituiría una déplorable añagaza el hecho de que, con el propósito de escapar a esos inconvenientes, se rechazara todo el aparato que los hace posibles. La justicia, en una sociedad de seres dotados de una inteligencia y de una voluntad falibles, puede adquirir la seguridad, la firmeza y la precisión necesarias, tan sólo en tanto se exprese en un sistema de reglas conceptuales, y en tanto que se desenvuelva por los cauces de un conjunto complejo de procedimientos.

Si bien es verdad que la injusticia se hace más odiosa cuando se cubre de hipocresía, sin embargo, todo ese aparato la limita y la hace más soportable, al forzarla a darse una vestidura jurídica, cuyo porte la obliga a muchas limitaciones y estorba lá libertàd de sus movimientos.

Así pues, el Derecho, al igual que toda actividad humana, está sometido a la ley de nuestra condición de seres espirituales encarnados, cuyo pensamiento no puede cobrar conciencia de sí mismo más que expresándose por palabras, y cuya voluntad se convierte en señora de sus actos tan sólo en tanto que se organiza en forma de hábitos. Pero estamos incesantemente amenazados por la inercia de los.instrumentos que establecemos, y tenemos necesidad de reajustarlos constantemente, para no convertirnos en esclavos de ellos.

En 'casos extremos, sucede que este esfuerzo de liberación debe adoptar una forma violenta. Ningún jurista, ningún moralista podría proscribir la resistencia contra las leyes injustas o incluso contra el poder que se opone sistemáticamente a la misión que debe servir y la contradice. No admitir esto equivaldría a justificar y consolidar todas las tiranías.

Pero esta resistencia puede ser admitida tan sólo de un modo excepcional. No se debe olvidar que el orden social, y la paz que deriva de éste, son bienes muy preciosos, y muy necesarios para la realización normal de nuestros fines morales. Por eso, el orden y la paz merecen sacrificios; y, por eso, su salvaguarda pertenece a la esfera de nuestros deberes de justicia social. Cuando se ataca el orden establecido nunca se sabe hasta dónde se extenderá el quebranto que se le haga sufrir. Cuando, se trata de poner remedio a una injusticia, es posible que esto traiga consigo riesgos mucho más grandes.

Lá desobediencia y la insurrección deben quedar subordinadas a requisitos muy estrictos, que rara vez se cumplen: la existencia de una injusticia grave, manifiesta a los ojos de un hombre prudente e informado, imposible de ser remediada por vías legales; y que se posea probabilidades serias de hacer cesar esa injusticia, sin producir males más graves.

Volviendo de nuevo al problema de la interpretación, dice Husson que es un craso error el pensar que el intérprete podrá sacar la solución -para todos los casos concretos valiéndose de una deducción rigorosa, que arranque de un conjunto de textos imperativos; y el pensar que el legislador, para elaborar sus textos no tendría sino que aplicar un pequeño número de principios que 
se impondrían a su conciencia con una evidencia arrolladora y con la precisión tajante de los axiomas matemáticos.

Pero entrañaria un peligro todavía más grave el abandonarse a un impresionismo o a un intuicionismo jurídico, que dejara a la libre apreciàción las decisiones del juez o los preceptos del legislador. No se olvide que el juez y el legislador no son necesariamente seres con una integridad moral perfecta. No se olvide tampoco que la imposibilidad de prever en alguna medida el veredicto mantendría la vida social en una incertidumbre. $Y$ téngase en cuenta además que el espíritu humano, para ver claro en problemas que son inmensamente complejos y matizados, necesita apoyarse sobre análisis precisos, y sobre la enseñanza de la experiencia.

Por consiguiente es necesario usar la inteligencia lógica, pero sin abandonarse completamente al automatismo de ella.

\section{Conclusión}

Husson, como resumen de su pensamiento dice que el Derecho no es pura técnica. Tiene autoridad sobre nuestras conciencias tan sólo porque la técnica en la que encarna aparece a éstas como un medio para la realización de fines éticos. Tiene valor tan sólo en la medida en que se subordina real y efectivamente a esos fines.

Para desempeñar su papel de regulador de las sociedades humanas, el Derecho tiene que traducirse a reglas conceptuales, regidas por una lógica estricta, que imprimen una dirección firme a las voluntades individuales, y que organizan instituciones netamente definidas. Ahora bien, tales reglas y tales instituciones implican una gran parte de artificios. Por eso reclaman una constante adaptación y readaptación. Esas reglas y esas instituciones son beneficiosas y pueden conseguir aceptación, tan sólo en tanto que forman un conjunto bien articulado, cuyas partes se corrigen y se equilibran. Y deben ser siempre vivificadas por la idea que ellas encarnan.

Así pues, el jurista es mucho más que un técnico. Es necesario que en el jurista el técnico se subordine a un artista, es decir, a un verdadero creador de orden social y de justicia; cuya obra supone intuición; y, al mismo tiempo, es necesario que se convierta en un sabio que constate con rigor y con probidad los datos. Pero este arte y esta ciencia no pueden cobrar sentido sino en la medida en que destaquen su carácter ético. Y este carácter ético, a su vez, expresa toda una metafísica, si es que no una religión.

En la época en que el mundo moderno se ha derrumbado en sus bases, y en que la humanidad, bajo la amenaza de perecer, está obligada a construir un orden nuevo, es indispensable que los juristas, cuyo papel en esta reconstrucción debe ser capital, cobren conciencia de la amplitud de su misión, y es necesario que no titubeen en volver su vista hacia las perspectivas lejanas, 
de las cuales puede:llegarles la luz necesaria para guiarlés en su tarea. El Derecho, al igual que la política y la moral, implica, quiérase o no, una cierta concepción del destino humano. Es más, el Derecho es uno de los instrumentos para la realización de este destino. Mediante sus tanteos, sus fracasos y sus éxitos, el Derecho constituye una experiencia de alcance metafísico, de la cual debemos recoger los frutos para mejorarlo sin cesar, revelándonos a nosotros mismos nuestra naturaleza y nuestra vocación, a saber: la naturaleza y la vocación de un ser sujeto a necesidades materiales que le ponen en concurrencia con sus semejantes, aunque no pueda satisfacerlas sino en cooperación con ellos, pero llamado a elevarse, por medio de la justicia, a una vida espiritual, que requiere una comunidad con ellos y que se consuma en la misma.

- Luis Recaséns Siches 